\title{
Fei Xiaotong's Comparative Theory of Chinese Culture: Its Relevance for Contemporary Cross-disciplinary Research on Chinese 'Collectivism'
}

\author{
CARSTEN HERRMANN-PILLATH
}

\begin{abstract}
This article argues in favour of the triangulation of emic and etic methods in the comparative study of culture, taking China as a case. Starting from an indigenous theory of cultural comparisons, Fei Xiaotong's concepts of 'group pattern' (tuanti geju) versus 'differential pattern' (chaxu geju), I review the contemporary literature on 'collectivism' in social psychology and management sciences. The article shows that Fei anticipated major revisions of this concept, resulting into a multi-aspectual approach that distinguishes 'individualism', 'collectivism', 'vertical/horizontal relations' and 'relational/categorial embeddedness'. In this frame, Fei's characterisation of Chinese culture can be restated in terms of the aspects of 'individualism', 'relational embeddedness' and 'verticality'. I argue that Fei's anticipation of modern research may be rooted in a feedback of culturebound cognition to theory formation. Taking Chinese networks and Chinese popular religion as examples, the validity of this approach is further confirmed.
\end{abstract}

Keywords: Chinese culture, collectivism, Fei Xiaotong, field dependence, guanxi, Chinese religion

\section{Introduction}

The study of culture is cross-disciplinary in essence, though this does not mean that the various disciplines communicate among each other and strive to establish a genuinely transdisciplinary approach. ${ }^{1}$ In this article, I try to develop a transdisciplinary perspective on Chinese culture, drawing on various resources and insights - in particular from psychology, management sciences, sociology and anthropology - and relate these to one of the most influential indigenous theories of Chinese culture: the theory of the 'differential mode of association' (chaxu geju), proposed by the eminent Chinese sociologist Fei Xiaotong 70 years ago. ${ }^{2}$ I aim towards an integration of etic and emic approaches 
to culture, arguing in favour of a balance between 'indigenization' and 'universalization' in the study of culture. ${ }^{3}$ Many approaches to culture try to establish an etic frame of reference for locating different cultures, even claiming that it is possible to quantify cultural differences. The emic perspective is mostly elaborated in the humanities and cultural studies, relying on interpretive and hermeneutic approaches. In this article, I adopt an emic perspective, in a double sense: 1) to look at an indigenous theory of cultural comparison and 2) to use this theory in re-arranging the results of the etic research. I do not present original research on cultural differences in the sense of new primary data, surveys or experiments, but rather develop a new interpretive frame that builds on an indigenous theory. I will show that such an integration might build upon more foundational phenomena in cognition (as seminally proposed by Hong and Chiu 2001).

The lack of cross-disciplinary communication mainly reflects divergent methodological standards. In particular, economics and management science rely heavily on quantitative methods in order to gauge the impact of culture on individual behaviour or larger patterns of social phenomena (for recent surveys of this research, see Guiso et al. 2006 or Beugelsdijk and Maseland 2010). In doing this, they often use input from psychology, which also values measurement and experiments. Beyond this, economics and management sciences rarely, if ever, take insights from cultural studies or anthropology, which mostly concentrate on 'thick description' of ongoing changes in Chinese society, into consideration.

My workhorse in this article is the 'individualism vs. collectivism' dichotomy, which has paradigmatic status, especially in comparative research about 'East Asian Culture' vis-à-vis 'Western culture'. Thinking in terms of this dichotomy is extremely influential in the management sciences and psychology, exerts strong impact on special fields such as cross-cultural management, and has thus eventually become commonplace in training courses for expats, diplomats and other highly mobile professionals. In addition, statements like 'the Chinese are collectivists' often go hand in hand with labelling China a 'Confucian' country. The implications of such characterisations are profound as they also impact, for example, on evaluations of political culture, such as when the Chinese are regarded as being culturally inclined towards accepting authoritarian rule based on strong collectivist moral norms.

At the same time, the topic of individualism has emerged as a vibrant research issue in Chinese studies, informed by sociology and anthro- 
pology and mostly based on detailed case studies (for a representative collection of papers, see Hansen and Svarverud 2010 or Kipnis 2012). Whether and how 'the Chinese' are becoming more 'individualistic' as a result of the ongoing seismic changes and disruptions in the past seven decades of Communist Party rule in China is a fascinating, if not close to paradoxical, question. This is because, as Yan Yunxiang has argued in a number of seminal contributions, 'modernisation' in China continues to be state-led and even the active promotion of 'individualistic' values and behaviours takes place within the context of what basically remains an authoritarian system of political and social governance. ${ }^{4}$ The paradox springs to the eye: implicitly or explicitly many observers of China believe that China is moving from a more 'collectivistic' society towards a more 'individualistic' one. However, this move is being orchestrated within a larger political framework, which apparently remains strongly 'collectivistic' not only in ideological terms, but also with regard to many social practices, for example, in the education system.

In this article, I approach these issues from the perspective of Fei Xiaotong's comparative theory of Chinese society. This theory exerts a strong influence on Chinese sociology and anthropology, though it is treated as controversial, especially with regard to its relationship to modernisation, as it is empirically grounded in Fei's research on rural society. ${ }^{5}$ However, as pointed out by Gary Hamilton (2014), by and large it has only been partially received; Fei's parallel account of Western society is rarely even considered, as also noted by Yan Yunxiang (2006). This is a major focus of my argument. Fei's theory is an important contribution to the comparative study of culture, because it sheds a different light on categories for classifying cultures that originated in Western research.

The article proceeds as follows. I begin with a brief outline of Fei's theory. Next, I summarise recent developments in research on individualism and collectivism, resulting in a multifaceted view that concurs with Fei's theory. Thus, I claim that Fei's theory offers a more powerful conceptual frame for cross-cultural comparisons than the standard dualism of individualism vs. collectivism. I explore the deeper foundations of this approach in modern cognitive science approaches to culture, thus anchoring the emic perspective in an etic approach, concluding my methodological triangulation. I apply the new perspective to two topics in which issues of emic analysis and comparisons between Western and Chinese notions loom large: the concept of 'networks' as guanxi, and how to conceptualize 'religion' in China. 


\section{Fei Xiaotong's Theory of Chinese vs. Western Society}

Fei Xiaotong (1910-2005) was one of the most influential Chinese sociologists of thetwentieth century. He studied anthropology with RadcliffeBrown and Malinowski in England, later returning to China for fieldwork that is documented in important English-language publications (Fei 1939, Fei and Chang 1945). Based on his village studies, he developed new concepts for rural development, especially rural industrialisation and township development. Like most returned intellectuals, he suffered extreme repression during the Cultural Revolution, but after his rehabilitation his ideas became very influential in the design of rural economic reforms. In his book Xiangtu Zhongguo (English translation: From the Soil. The Foundations of Chinese Society, see note 2), Fei develops a theory of Chinese and Western culture that builds on the idea that the patterns of group formation differ cross-culturally. In Chinese studies Fei is mostly known for his distinctive analysis of Chinese society in terms of his neologism chaxu geju: the second term just means 'pattern', whereas the first term is complex and often misunderstood. The term 'cha' refers to horizontal social relations, in the sense of distances between individuals in concentric social networks, and the term ' $x u$ ' refers to the vertical dimension, in the sense of a rank order. As such, the term remains abstract and almost devoid of specific meaning. It only gains significance in the comparative context.

Fei proposes the term 'group pattern' for describing Western society; 'tuanti geju' means that Western societies emphasise ascriptive ties to abstract collectives as compared to Chinese society, which emphasises relations among concrete people (what Fei calls 'social circles' or shehui quanzi). Interestingly, Fei does not refer to the distinction between individuals and groups in the first place, but to two different principles of group formation. This introduces a fresh perspective on cross-cultural comparisons as Fei does not treat 'individualism' (geren zhuyi) as the foundational criterion for characterising Western society as different from China. ${ }^{6}$

Accordingly, he also posits two different forms of individual-oriented behaviour. 'Individualism', in this more general sense, is not opposed to the notion of the group, but appears to be a concept that refers back to the specific pattern of group formation, hence to agency. So, in his view, 'individualism' in the Western sense approaches individuals as being 'equal' in terms of abstract membership criteria, which implies that individual agency is actually a derivative of the group (so, for example, being conceived as being based on 'rights'). Fei even states that the group 
is therefore primordial for Western individualism. In contrast, Chinese society is classified as 'egocentric' (ziwozhuyi), implying that agency and values are exclusively related in the 'self' (ji). The distinction is that Western individualism, in treating individuals as abstract members of groups defined by categories (such as 'the nation'), actually adopts a 'decentred' perspective on the individual, whereas Chinese society emphasises the pivotal position of ego in defining the nature of personal relationships, and thus defines every individual according to positions in these different egocentric networks, thus as 'unequal' per se. One important implication is that in the Western case, the entire set of social relations is seen as being embedded in an encompassing order defined on the level of the categorial group (for example, individuals being citizens of a nation), whereas in the Chinese case social order consists of the entire set of individualised, 'egocentric', and overlapping social circles.

In a famous remark, Fei described social relations in China as the ripples that appear in a lake when pebbles are thrown into it; the ripples overlap and interfere with each other. We can interpret his theory in terms of two different patterns of network formation (see Figure 1).

FIGURE 1. Chinese and Western networks.

Western Networks
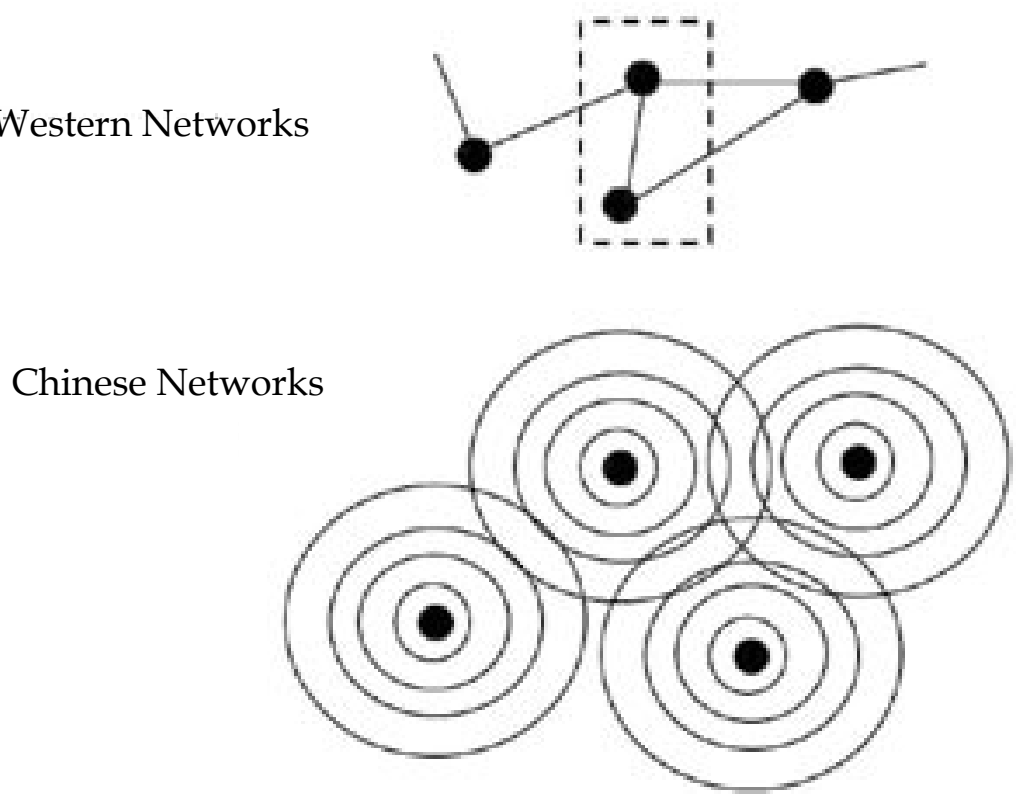

In the Western network, nodes (individuals) and relations or connections are clearly separated, and certain nodes may form groups that are neatly delineated by group borders defined by categories. In the Chinese 
network, nodes are centres of circles that can expand or shrink (indigenously denoted as 'small self' (xiao wo) vs. 'big self' (da wo), see Chang and Lee 2012). Groups are established by the interferences between the circles, and thus have fuzzy borders.

Fei claims that this distinction raises important methodological issues in Chinese studies, because specific kinds of groups differ. A case in point is his discussion of the family and the lineage. Fei criticises the standard notion of the family and the lineage in Western social science because it supposes a neat vertical integration and clearly defined membership criteria. On the contrary, the Chinese notions are fuzzy and open-ended, adapting to the functional needs that emerge in specific social and economic contexts. ${ }^{7}$

What I have discussed so far is the cha 'distance' aspect of chaxugeju. The $x u$ 'rank' aspect has already been introduced (the conceptualisation of society as being structured by hierarchical distinctions) and remains always defined as relative to ego, and not relative to an abstract collective. So Fei combines egocentrism with verticality and adds his notion of social relations. The hierarchical aspect relates to another fundamental distinction that Fei introduces, namely between 'ritual' (li) and 'law' $(f a)$. He argues that Western views falsely suggest a dichotomy of social order between 'rule by men' vs. 'rule by law', whereas the Chinese case suggests a third alternative, rule by ritual. Ritual is a set of social mores, customs or even customary laws, which is not enforced by a political body, such as the state, and which is adopted via socialisation in groups, specifically the village. The main role of ritual is to define a rank order. ${ }^{8}$

Accordingly, in dealing with Fei's theory, one limitation needs to be considered: Fei argues that the Chinese model of 'ritual' mainly applies for village society, as it rests upon custom and personalised relationships, and cannot work in a modern urban society. In this sense, the 'rule of law' also appears to be the standard towards which Chinese modernisation will inevitably converge. However, in this juxtaposition between rural and urban society Fei does not consider the fact that already in Imperial China, ritual was deeply enmeshed with law and also played an important role in urban society. This critical reflection opens up perspectives on generalising from Fei's theory as a crosscultural framework for considering contemporary culture as well (see also Yan 2006). 


\section{Beyond Individualism and Collectivism: Recent Research in Social Psychology}

If we compare Fei's theory with recent comparative approaches to culture in 'Western' research, it is immediately apparent that the direct juxtaposition of 'individualism' vs. 'collectivism' looms large. Typically, Western society is described as being more 'individualistic' and Chinese society as 'group oriented'. This is also often approached in terms of a polarity in one single dimension. Accordingly, cultural change is often perceived as a process of 'individualisation', shifting from 'collectivism' to 'individualism'.

The distinction between individualism and collectivism is one of the best validated conceptualisations of cultural differences across countries and is used as an analytical commonplace across many disciplines. In management science and its applications, is Geert Hofstede devised one of the most influential approaches, also widely taught in cross-cultural training courses. ${ }^{9}$ Hofstede uses a set of survey questions to identify degrees of individualism vs. collectivism within one single dimension. As is well known, China scores very low in individualism, and high in other relevant dimensions, especially 'power distance' (the attitudes of people towards higher level authorities). However, during the past three decades, China has also played an important role in driving modifications and amendments of the Hofstede approach. This is because when the Hong Kong-based psychologist Michael Bond designed a 'Chinese Value Survey' based on different survey data, he could basically confirm Hofstede's identification of four cultural dimensions (individualism, power distance, uncertainty avoidance, and masculinity). However, he also discovered that there is another mediating dimension, which was then introduced as the 'fifth dimension' into the Hofstede scheme, namely 'long-term orientation'. In this dimension, East Asian societies lead all other nations in the world. However, the dimension also proved to be statistically unstable, so that in the most recent versions of the Hofstede approach, this dimension was partitioned into two, 'long-term orientation' and 'indulgence'. China scores very high in the former and low in the latter. ${ }^{10}$

In management science, another very influential study is the GLOBE survey, which concentrates on the issue of leadership in business, but includes broader perspectives on culture and society. ${ }^{11}$ The GLOBE survey keeps the distinction between individualism and collectivism, yet adds two modifications that are important in the context of my dis- 
cussion. The first is distinguishing between behaviour and practices as they actually occur in different societies ('as is') and values as normative expectations ('as should be'). The second is distinguishing between 'institutional collectivism' and 'in-group collectivism'. The former refers to individual expectations regarding institutionalised patterns of grouporiented behaviour, such as redistribution by the government. The latter relates to behaviour in the context of individual reference groups such as family and kin.

The distinction between practices and values is of great methodological importance in value surveys because a value proposition can be either a statement about what is appreciated as actual practice or an assertion about a desirable state that is not actualised in practice. This means, for example, that a 'collectivist' might be either somebody who appreciates current collectivistic practices, or somebody who desires a strengthening of collectivism, compared to actual practice. As a result of this ambivalence, comparisons across countries can become very difficult. ${ }^{12}$ According to the GLOBE survey, China scores high in the 'societal institutional practices' dimension, where it compares with countries such as Sweden or Ireland, as well as with other so-called 'Confucian countries'. China's 'societal collectivism values' score is close to the practices score, but the comparative country pattern differs considerably from the values perspective. In terms of values, China does not belong to the group with the highest scores, which includes many Latin American and South European countries, and only Taiwan (score 5.15, compared with Mainland China's 4.56) of the so-called 'Confucian' countries. China groups together not only with Germany, but even with the Netherlands (score 4.55), which is the prototypical 'individualistic' country in the Hofstede approach (individualism score 80 vs. China's 20). Regarding the 'in-group collectivism values' score, the results are astounding, because all countries score at a relatively high level, but China is actually the third lowest value in the entire set (5.09), which would nevertheless imply an appreciation against practices. Yet, the group with lowest scores includes Germany, the Netherlands or South Africa, whereas the countries with the highest scores are mostly Latin American ones, and also, for example, New Zealand.

The GLOBE approach raises another important question that is also discussed by Hofstede, namely whether the measurement of values covers individual-level phenomena or only society-level ones, which could also be understood as the distinction between 'psychological' and 'sociological' conceptualisations of values. Psychologists have always 
been very sensitive towards this distinction, therefore we find another conceptualisation here, referring exclusively the to individual level: 'idiocentrism' and 'allocentrism' (Triandis 1989). As I will argue later in more detail, the distinction between psychological and societal levels is extremely important for understanding the impact of institutions on current behaviour and the potential channels through which certain values are transferred across generations. Although on the one hand Hofstede observes this difference, on the other he argues that culturally transmitted values amount to 'mental programming', so leaving no leeway for psychological phenomena to differ from what might just be an institutionally determined behaviour. ${ }^{13}$ This question is important for Chinese studies, since regarding the collectivism dimension, we need to recognise an extremely disruptive institutional change in the past three decades. One of the paradigms for understanding Chinese society in the 1980s, Walder's 'communist neotraditionalism', clearly emphasised the role of institutions in determining psychological attitudes such as 'organized dependence'. ${ }^{14}$ Today, Yan Yunxiang highlights the fact that individualism is rising in Chinese society because of state-imposed changes of institutions. ${ }^{15}$

In psychology, the simple dualism of 'individualism' and 'collectivism' has been thoroughly questioned in recent decades. This reflects the fact that in the original Hofstede approach, 'individualism' appears as mostly characterising a certain number of Western protestant societies, whereas collectivism often goes along with large power distance, a combination which covers a very large number of countries which vary widely in cultural terms. In other words, the Hofstede cultural scores are not sufficient for identifying cultural differences within this large group. Further, if one goes back to the original survey questions in identifying collectivism, these questions often appear to be much less specific to collectivistic norms than the apparently clear-cut conclusions suggest. ${ }^{16}$

One particularly difficult problem is that in many psychological experiments 'individualistic' individuals can also manifest strongly collectivistic behaviour. Further, it is difficult to disentangle the impact of other dimensions on the individualism/collectivism distinction. Hofstede often suggests that certain behaviours which might appear 'collectivistic' in cases that have been characterised as 'individualistic' societies allegedly reflect different degrees of power distance or masculinity. ${ }^{17}$ In order to clear up this confusion, two additional distinctions have been introduced in the literature. 
The first is 'verticality' versus 'horizontality', which applies for both collectivism and individualism and identifies different expressions of the two fundamental values in different societal contexts. ${ }^{18}$ It is important to note that these additional distinctions vary independently, so that we can have the juxtaposition of a 'vertically individualistic' society and a 'vertically collectivistic society', or we can have the juxtaposition of a 'vertically' vs. a 'horizontally collectivistic' society, for example. The criterion of 'verticality' catches what is a relatively murky interaction between power distance and individualism/collectivism in the Hofstede framework. A vertical form of both individualism and collectivism means that society is geared towards the emphasis of status differences between individuals and emphasises competitive behaviour in advancing in the status hierarchy, whereas in a horizontal society, individuals mutually respect each other and aim at creating a cooperative environment allowing for equal opportunities in self-expression. Vertical individualism results in behaviour that is strongly competitive in pursuing individual achievement goals, whereas vertical collectivism emphasises authority relations in groups which in turn may stay in a competitive relationship with other groups. In comparison, horizontal individualism will emphasise individual emotional needs and self-expression in interpersonal relations.

It is straightforward to recognise that these distinctions help to clarify some empirical difficulties with the original Hofstede dichotomy. Taking the US and China as examples, the US is classified as a vertically individualistic country, whereas China might appear to be vertically collectivistic, on first sight. Between both societies, however, certain phenomena might be similar as compared to horizontal individualistic Scandinavian countries, for example. This is particularly the case with competitive behaviour in status hierarchies, or social acceptance of expressions of status differences, such as wealth.

The second distinction that has been introduced in the recent literature goes back to research in social psychology that questions another aspect of the original individualism/collectivism dichotomy, which has been partly recognised in the GLOBE survey. This is that collectivism may refer to two different kinds of groups, namely abstract categories of people versus interacting networks of people. So, we can distinguish between 'categorial collectivism' vs. 'relational collectivism'. ${ }^{19}$ Categorial collectivism means that individuals assign themselves to abstract categories such as the nation, the company or the race, which are 'groups' of much wider scope than networks of actually interact- 
ing, even similar, people (in large companies, members do not interact with everybody). In contrast, relational collectivism refers to patterns of actual interaction, such as networks of friendship or professionals in a department within a large company. Further, this literature argues that individualism and collectivism refer to two qualitatively different psychological phenomena: individualism relates to ideas about agency, collectivism is a value system. This means that the two do not belong to one dimension and hence can combine freely. Thus, there can be new combinations with the individualism feature, because, for example, categorial collectivism about values may combine with individualism about agency in certain cultural settings. For example, considering the fact that Hofstede originally concentrated on work environments, there are many results showing that Americans, though appearing to be the classical individualists elsewhere, manifest strong 'categorial collectivism' in a work environment, thus strong loyalty to the organisation, and suppressing expressions of individual emotions in their relations with others. In contrast, the Chinese also emphasise the importance of individual emotional satisfaction in work-related interactions. ${ }^{20}$

The question emerges whether we can also apply this distinction to the notion of individualism. Relational individualism would then refer to behaviour by which individual goals are mainly satisfied in interactions with other people, and categorial individualism would concentrate on more abstract relationships, such as achieving certain professional goals defined in individualistic terms. This possibility has been explored in earlier Chinese studies contributions, which introduced notions such as 'relational personalism'..$^{21}$

Summarising the results of this section, we end up with a multi-aspectual space in which we can locate individual values and behaviour:

- Verticality vs. horizontality

- Categorial vs. relational embeddedness

- individualism

- collectivism

Regarding individualism, this refers to where individual motivation, criteria for achievement and notions of agency are located, in the individual or the collective. Thus, the category comes close to more abstract notions such as 'autonomy'. We now have a much larger number of possible combinations, such as, for example, individualism, relational embeddedness and verticality, as compared to collectivism, categorial embeddedness and horizontality. Individualism and collectivism are no longer two poles in one single dimension. 
In discussing these observations, I do not raise an empirical claim in the first place, but a conceptual and even philosophical one. Empirically, we would identify certain 'types' of society not via these abstract categorisations but via a historical-genetic approach. This distinction is mostly blurred in research on values. For example, in our context, the GLOBE survey only characterises one group of societies by referring to a certain philosophy, Confucianism. Others are simply grouped together by geographical criteria. Without reflecting upon these different typologies, in the case of the 'Confucianism' group, the hypothesis is submitted that all these societies were shaped by one particular ideological system, namely Confucianism, over a very long time span..$^{22}$ This raises the important question of how indigenous conceptualisations of values and social structure relate to the theoretical psychological categorisations, whether we can establish a correspondence between emic and etic approaches (Kulich and Zhang 2010).

If we reflect upon this result in the context of Fei Xiaotong's theory, it is straightforward to see that Fei anticipated these recent developments in social psychology. He analysed Chinese culture in both the aspects of individualism and the patterns of group formation, with the relational type clearly corresponding to his concept of 'circles'. A generic conception of 'individualism' does not help to distinguish between Chinese and Western culture, as there are also different forms of agency related to the dynamics of group formation. Further, Fei's notion of chaxu highlights a particular form of vertical order.

This observation raises an interesting question: why does Fei recognise certain structural principles in the comparative study of culture that were only gradually discovered by research in social psychology decades later? One interesting hypothesis would be that this is, in turn, rooted in cultural differences that become manifest in the way theories in social science and psychology are formed. More specifically, cultural forms of cognition may influence both the way theories are formed and how behaviour is shaped. I will explore this idea in the next section.

\section{Culture and Cognition}

In spite of the clear evidence against 'collectivism' as a simple characterisation of Chinese culture, the question is still open how we can reconcile this insight with case-related evidence and specific survey results that highlight apparently 'collectivistic' attitudes. As we have seen, one important issue in the original surveys is whether the results 
actually catch individual-level psychological variables or society-level values that are to a large degree institutionalised. What is the connection between the two levels? How far do 'internal' or 'external determinants' drive behavioural phenomena?

One way to connect the two is to introduce the notion of 'framing', which has become very prominent in behavioural economics recently. In economics, 'values' are conceptualised as 'preferences', institutions as 'constraints'; the traditional distinction between 'individualism' and 'collectivism' corresponds to the distinction between 'individual' and 'social preferences', with the latter seen as 'other-regarding preferences' or as preferences that are socially shaped and embedded. Recent research has presented evidence that there are strong framing effects on the individual level. This means, depending on the frame, that the same individuals manifest different degrees and combinations of individual and social preferences. ${ }^{23}$ This insight matches with the ecological theory of culture proposed by Yamagishi (2012). In this theory, individuals act as 'cultural game players' who adapt their behaviour to certain cues and signals they receive from the environment. In his comparisons between Japanese and Western subjects, he reached the conclusion that East Asians are not 'collectivistic' or 'individualistic' per se, but that they act in a collectivistic way if they receive certain information about the context of their actions, in particular about the expectations of others. For example, Japanese subjects show even stronger 'individualistic' behaviour than Caucasians if they act in an anonymous setting. ${ }^{24}$

Therefore, one way to reconcile the different data is to dig deeper into the cognitive determinants of social perceptions and decisions that connect frames with behaviour. Yamagishi follows Nisbett here, and argues that there are two fundamentally different cognitive stances: field dependence vs. field independence. ${ }^{25}$ Apparently, 'collectivistic' behaviour appears more often under conditions of field dependence because individuals pay more attention to social context and cues about the behaviour of others. For example, in one experiment Chinese and American subjects react differently to the same framing because they manifest different tendencies to cheat if they learn about the readiness of others to cooperate. This means that whereas the Americans appear to act field-independent in taking the immediate incentives for cheating as predominant cognitive cues, the Chinese pay more attention to the expectations of others regarding proper behaviour. ${ }^{26}$

There are two central insights to take from Yamagishi's theory. Firstly, values are not simply 'mental programming' but emerge from 
interactions between social cognition and frames. Frames are generated by the institutions of society, so there is a strong impact on behaviour that goes beyond the direct impact of incentives and sanctions that undergird the institutions. This also means that behaviour can change rapidly if institutions, and consequently the framing effects, change. There is no strong and immutable effect of 'ingrained' values on people. Secondly, and modifying this assertion, there are effects of social cognition on behaviour which channel the reactions of individuals to frames. This might result in cross-cultural differences in behaviour that are more persistent, but also more indirect. The distinction between field-dependent and field-independent cognition resonates with earlier distinctions the cultural theory, such as Hall's (1976) notion of 'high' vs. 'low context' cultures.

There are different explanations of cognitive differences across people. Nisbett himself proposes that these are deeply rooted in history. Related theories, also well-known in Chinese studies, emphasise the role of agrarian ecologies, especially the difference between rice growing communities and those working with wheat agriculture, with both historical and contemporary impacts. Obviously, the intermediating causal variables cannot be the ecologies per se, but the institutions that emerge under these conditions. ${ }^{27}$ As Yamagishi emphasises, the problem is how to explain the persistence of these ecological factors in a changed technological and social environment. One possible explanation might be institutional path-dependencies that retain causal power even if the ecological determinants no longer work.

Now, one interesting consequence of this analysis is that such fundamental cognitive patterns may also affect the way theories about social structure and relationships are formed by scientific observers. In other words, research would turn reflective on a meta-level. This leads back to the question of how Fei Xiaotong anticipated recent advances in social psychology in his theory. Linking cognitive science and methodology in the study of culture has recently been advanced as a possible foundation for indigenous theorising in the management sciences, for example, in the context of the so-called 'Yin Yang' approach (see Fang 2012, Peter Li 2014; Li Xin 2014). This approach argues that the Yin-Yang model reflects a particular stance towards dialectical thinking that also has a direct impact on the way concepts are formed and applied in science. For example, the Hofstede approach clearly fits with Fei's criterion of ascriptive group formation, as Hofstede assumes that all Chinese would fit into the same category. In comparison, the Yin-Yang thinking would 
render 'collectivism' as a flexible aspect of behaviour that can easily cooccur with other aspects, even those that are apparently contradictory. This means, in the context of this section, that one could argue that Yamagishi's ecological theory is itself the reflection of field-dependence in theory formation.

Thus, we can conclude that the study of culture necessarily rests upon a multi-level entanglement between emic and etic approaches. In particular, the etic approaches may themselves be culturally embedded. Modern cognitive science provides the foundations for the indigenisation of cultural theory in opening the view on possible feedbacks between culturally bound cognitive stances and theory formation.

\section{Guanxi and Chinese Individualism}

I will now apply the conceptual framework developed thus far to the (in)famous notion of guanxi: allegedly a specifically Chinese pattern of social networks and related practices of network formation. However, the status of the term guanxi is ambiguous. In Chinese studies, there are influential and important usages, but also serious limitations. In the light of Fei's work, the notion of guanxi would mainly apply for rural society, suggesting substantial changes during urbanisation and modernisation. In contemporary urban society the term is often associated with corruption; accordingly, the prevalence of guanxi might be a transitory phenomenon reflecting weak institutions, especially lacking rule of law. ${ }^{28}$

However, beyond Chinese studies the term is experiencing a very strong intellectual career. This is mostly supported by the contributions by scholars with a Chinese background in management sciences (for a recent survey, see Chen et al. 2013). So there is still a need to clarify some aspects of guanxi. This should be done, however, against the larger background of Chinese studies. Whereas outside Chinese studies the term often assumes paradigmatic status, in Chinese studies it has been recently seen as only one phenomenon in a larger pattern that is traditionally denoted as the principle of li shang wanglai, which roughly translates as 'courtesy requires proper response'. ${ }^{29}$

If we go back to standard definitions of guanxi, it is intriguing to observe that guanxi are actually an expression of egocentrism, in Fei's sense. This is important for two reasons. Firstly, guanxi are always relative to ego. For example, in Jacob's influential guanxi model, what counts is 1) perceived and activated similarities between individuals 
and 2) emotional foundations for instrumental relations (1982). For both reasons, we cannot simply equate guanxi with clientilist networks, which concentrate on one particular individual as a reference (a patron) or with categorial networks, which would define membership independently from the individuals in question (such as a professional association). Guanxi are egocentric in the sense that they are highly personalised, and this is further bolstered by emotional bonds that are not dependent on particular types of given social structures (such as the family), but which are created endogenously in contingent social interactions. Without discussing guanxi as such, Fei argued that notions such as 'neighbourhood' or 'family' may appear like 'groups' in the Western sense, but in fact are 'open circles of social relations' or shehui quanzi. This openness, fluidity and egocentricity is a defining feature of guanxi. ${ }^{30}$

Another important characteristic of guanxi is that they rest upon social creativity driven by individual actions. Guanxi are individual investments in social capital that is of the 'Burt type' in the first place; that is, they bridge structural holes in networks to reap individual advantages. ${ }^{31}$ Even if guanxi of this type coalesce into stable cooperative relations, the essential point remains that the agent who maintains the guanxi is the individual, and that benefits of cooperation accrue to the individual (which means, these are collective goods, but do not necessarily imply altruism). In this sense, we cannot equate guanxi with collectivism, but with relational embeddedness that combines with individualistic motivations. Clearly, if an individual 'pulls guanxi' the motivation is always an individual one, and is not primarily deduced from higher level collectives in the network in question.

Thus, we can regard guanxi as a manifestation of Chinese individualism combined with relational embeddedness, further confirming the analytical value of the new conceptual framework. One direct expression of this fact is the autonomy of the individual relative to guanxi: individuals decide upon the use of guanxi, they are not imposed on them. There is no absolutely binding commitment to guanxi transcending all social domains. This is a point that has been emphasised in the literature from the outset, but is frequently neglected in viewing guanxi as reflecting a supposed group orientation of the Chinese.. This view can be also supported by analysing the indigenous terminologies and narratives surrounding guanxi, especially with regard to the core notion of the 'self' that engineers guanxi. ${ }^{32}$

I argue that the study of guanxi actually bolsters the revisionist characterisation of the Chinese as 'individualists'. In this context, it is worth- 
while to look at the results of the most recent wave of the World Value Survey (WVS) in a little more detail. In the WVS, China, together with other 'Confucian societies', has a special position. Originally, the WVS was designed by R. Inglehart in order to construct a simple measure of 'modernity' on the societal scale (Inglehart and Welzel 2005). This effort resulted in a highly aggregate positioning of countries in a two dimensional map of 'modernity'. One dimension is defined by the poles of 'secular rational values' and of 'traditional values', while the other is defined by the poles of 'survival values' and 'self-expression values'. China is well advanced in the former dimension, but is still strong in survival values. It is most intriguing to see that this compares with the US and other English speaking countries (even cases such as Australia), which are still 'behind' China in terms of rationalisation, but far more advanced in self-expression values. China shares this peculiar position with other so-called 'Confucian' countries, in particular Japan, which appears to be the most 'rationalistic' country in the world, but still remains in the transition stage towards 'self-expression values'. ${ }^{33}$

It is worthwhile looking at a certain number of questions in more detail. In political science, one of the most reliable indicators for authoritarian attitudes is the set of values that people maintain in educating their children. The WVS contains a series of questions that give a somewhat unexpected picture of the Chinese. I compare the results for China, the US, Germany and Russia. The most glaring observation is that the Chinese lead the pack in avoiding mention of 'obedience' as a value that ought to be taught to children. Both the US and Russia are above the average for this value in this group of countries. On the other hand, the Chinese and the Germans are above the average in naming 'independence' as an important educational value, with the Chinese at 79 per cent, only slightly losing out against Germany. This result fits with other questions like whether the Chinese see themselves as being 'autonomous persons', where close to 80 per cent agree, whereas more than 50 per cent of Russians disagree. Only Germans have a stronger voice here.

Other educational values emphasised by the Chinese mainly relate to the traditional values of thrift and hard work, and there is low emphasis on imagination and creativity. So, what emerges is a picture of an achievement-oriented, secular society that recognises the active role and responsibility of the individual in shaping his/her future. ${ }^{34}$ This picture is also confirmed in general evaluations of the social context in which the Chinese perceive themselves. There is a pronounced belief, 
especially comparing with Russia, that individual success is determined by individual effort, and less by luck and connections. This matches with the perception of guanxi as being part and parcel of individual strategies and less related to clientilist obligations being enforced on the individual. The Russian case is always an illuminating comparison here, because Russians tend to perceive society as a zero-sum game, compared with the Chinese who appear to be very optimistic about life chances for everybody. Thus, regarding guanxi we can say that the corrosive effect of corruption and clientilism on society is evident in Russia, but cannot be confirmed for the case of China.

To summarise, guanxi, a term with a paradigmatic status, especially in Chinese management sciences, can be straightforwardly integrated into the three-dimensional scheme that I proposed previously and, in spite of affirming the importance of interdependence among individuals, it is a clear indicator of 'individualism' as a core value in Chinese society. Yet guanxi simultaneously include aspects of relational embeddedness and verticality, along the lines of Fei's original chaxu geju notion. However, we can observe that 1) guanxi dynamics turn hierarchical differences into accessible social capital also for lower status individuals, thus also weakening the pure relationship of dependence, and 2) the diverse nature of guanxi bases establishes forces of equalisation across hierarchical differences (such as shared native place equalising individuals with different status). This suggests important methodological consequences for understanding social structure. For example, a leading Chinese scholar in the field, Zhai $(2013: 35,47)$, argues that in the Chinese context it is not possible to clearly demarcate the micro- from the macro-level, thus manifesting the fundamental property of 'continuity' (lianxuxing). This is another case in point for the meta-level feedback loops that emerge in entangling the emic and etic perspective. ${ }^{35}$

\section{Chinese Religion}

My second example of the entanglement between etics and emics in the study of culture is religious studies and the well-known difficulties of defining Chinese religion. Here we observe an extremely interesting interaction between Western and Chinese conceptions that has even influenced the politics of religion in China. Empirically, we observe a paradox. In social science surveys, the vast majority of Chinese would designate themselves as being 'not religious'. At the same time, we notice a strong revival of religion in all shapes, in particular popular religion, 
but also the spread of Christianity. The case of popular religion is particularly interesting, as the Chinese state has adopted a legal definition that does not recognise popular religion, but only accepts religions as defined in a 'Western' sense, namely positing themselves within a formal organisation. These religions are also mainly seen as being 'modern' or in a modernised form (Islam possibly being the exception). ${ }^{36}$

If we reflect upon this phenomenon against the background of the previous analysis, it springs to mind that the current definition of 'religion' is categorial in nature; that is, it presupposes a clear-cut ascription of individuals to a certain religious belief system. Even when recognising the fact that in Chinese practice, these ascriptions often do not matter in the absolute sense, the requirement is at least that the 'religion' is represented as a category to which individuals might unequivocally refer.

This creates the difficulties in catching the essence of Chinese popular religion, as has been emphasised early by Yang (1961) in characterising Chinese religion as 'diffuse'. In a number of important recent papers on this issue, Adam Chau has used the concept of 'polytropy' to understand the phenomenon that Chinese religious behaviour cannot be described in terms of a unified set of beliefs and institutionalised settings but appears as flexible arrangements of practices that are aligned with different religious belief systems. These practices can be categorised into different types, called 'modalities': such as reading sacred texts or doing healing exorcisms. The modalities, however, are seen as reflecting generic religious needs individuals have (hence are not specific to the Chinese case). ${ }^{37}$ The practices themselves may be standardised, but their combination reveals a high degree of individual autonomy and creativity, which reflects the concrete needs of the individual. An essential term for understanding Chinese religion is the 'efficacy' (ling) of a practice, which is ultimately related to the fulfilment of an individual need, but which may be publicly recognised, thus motivating large numbers of followers. However, this behaviour is not based on assigning oneself to a public belief system, but to an experienced sequence of successful individual practices.

Obviously, Fei Xiaotong's framework is applicable here. Chinese popular religion appears to be 'relational' and open-ended, being a sequence and open set of practices. In fact, we can even argue that the principles of guanxi apply to religion, because what matters is the egocentric networks of individual relations with a large number of places and deities, with which the individual stands in a long-term exchange relationship. The individual donates (for example, offering incense), and 
the object of worship responds. This interpretation has been elaborated in much detail in Chang's 2010 analysis of the li shang wanglai framework, arguing that this does not only encompass social relations between the living, but also with the ancestors, and with deities and gods as well.

As Chau puts it in an illuminating comparison, whereas in Christianity the believer is host at Christ's table, in China the individual household hosts the gods and religious experts in order to pursue individual goals of prosperity and happiness. ${ }^{38}$ Indeed, his approach helps to explain much of the 'orthopraxy' vs. 'orthodoxy' controversy in Chinese studies. Practices are standardised and have to be observed, but they are modularised, which means that standardisation can affect various practices in different ways (such as only affecting parts of the funeral rites, in James Watson's famous example), and second, their ultimate meaning is rooted in the social creativity of the individual actors, thus transcending standardisation efforts by the government. ${ }^{39}$ We can in fact grasp the distinct nature of Chinese religion in terms of Fei Xiaotong's dichotomy: Chinese religion manifests the egocentric nature of using and expressing practices as rituals, and it cannot be defined according to abstract groups which identify themselves in terms of certain exclusive beliefs that are standardised in texts. So, Chinese religion is a clear expression of Chinese individualism. It is individualistic in terms of the egocentric use of rituals, and it is relationally embedded in being manifest in the social networks of different practitioners, religious experts, believers, spirit media, etc.

Yet, there is one feature of Chinese religion that matches with certain characterisations of 'churches' in the West: this is the hierarchical organisation of the world of gods and ghosts mirroring the organisation of the Empire, the conceptualisation of a celestial bureaucracy and the fact of partial state control of rituals and religious organizations. ${ }^{40} \mathrm{It}$ is straightforward to see this in the light of the verticality dimension. So, in current studies of Chinese religion, we find three aspects of individualism, verticality and relational embeddedness conjoined, as in the characterisation of Chinese culture.

Accordingly, Chinese popular religion can be seen as another manifestation of Fei's chaxu geju, also in the sense of balancing the aspects of horizontal networking and vertical order. It is probably for this reason that one particular analytical framework in understanding religion, the so-called 'religious market paradigm', has been fruitfully applied in the Chinese context. In this view, religious behaviour can be interpreted in terms of a supply and demand framework, and the specific structures 
of competition. I do not claim strong validity for this approach, but evaluate the observation on a meta-level: the empirical validity of the religious market model needs to rest upon the basic assumption of individualism, hence individual autonomy of choice. So, its applicability can further support my interpretation of Fei's framework. ${ }^{41}$

\section{Conclusion}

That Confucianism and collectivism go hand in hand is a commonplace and widely taught assumption about Chinese culture. I have not discussed the topic of Confucianism in this article, which concentrated instead on the empirical evidence regarding the 'collectivist' categorisation. This latter is important in Chinese studies because many researchers have recently discussed the 'individualisation' phenomenon resulting from recent reforms and social changes, thus implying that the starting point is a more 'collectivistic' orientation of individual values. Based on recent research in social psychology and cognitive sciences, I show that the 'individualism vs. collectivism' dichotomy is deeply misleading. I propose a multi-aspectual analytical approach that includes individualism as a category that grasps the location of agency in individual perceptions and social beliefs, and treats collectivism as a value stance. To this I add the aspects of 'categorial vs. relational embeddedness' and 'verticality vs. horizontality'. In this complex space, China attains the position of 'individualism' combined with 'relational embeddedness' in relation to 'collectivism', and 'verticality'. I further argue that this location is driven by the even more fundamental cognitive structures of field dependence.

This picture of Chinese culture concurs with Fei Xiaotong's indigenous theory almost exactly. So, one central finding of this article is that Fei's indigenous comparative theory of Chinese culture anticipated many of the insights of recent research on collectivism. This lends much support to clarion calls for the 'indigenisation' (bentuhua) of social and cultural research, which I interpret not only as 'ethnic indigenisation' but also as 'disciplinary indigenisation' (I already argued forcefully for this in Herrmann-Pillath 1996). The present discussion shows, as previously argued by Kulich (2010), that the study of culture needs to be based on triangulation approaches, conjoining emic and etic perspectives. The study of Chinese values runs the risk of serious errors if it is not combined with Chinese studies as generating confirming evidence. One such error is to classify the Chinese as 'collectivists'. This categorisation 
is widely used in management sciences, taught in cross-cultural trainings, and is used in economic and political science research on contemporary Chinese developments, apparently based on 'hard' quantitative evidence and sophisticated econometrics. Yet, feeding survey results about 'collectivism' into advanced statistical machineries may just be another instance of the 'garbage in / garbage out' fallacy. For example, if research on economic growth and social capital just takes quantitative data produced by common survey research as given, this may seriously distort not only our picture of China; it also affects the generalisation of results across countries (for instance, Bergren et al. 2008).

A truly transdisciplinary approach to Chinese culture would balance quantitative and qualitative aspects, or emics and etics. I argue that this must also become the benchmark in disciplinary uses of culture, as in economics. Projecting disciplinary methodological standards on a phenomenon that is transdisciplinary in nature is like the proverbial metaphor of four blind men touching different parts of an elephant, resulting in different and even incommensurable visions of the animal.

Carsten Herrmann-Pillath is Permanent Fellow of the Max Weber Center for Advanced Cultural and Social Studies, University of Erfurt, Research Professor of Economics and Evolutionary Sciences at Witten/Herdecke University, Germany, and Distinguished Visiting Professor of Schwarzman Scholars at Tsinghua University, Beijing. Research interests include economics and philosophy, institutional change and economic development, international economics, Chinese economic studies. He has authored 300+ academic papers and 16 books. His magnum opus China's Economic Culture: The Ritual Order of State and Markets is forthcoming with Routledge. Email: cahepil@online.de

\section{NOTES}

1 The research for this article was supported by the DFG-funded 'Research group on religious individualisation in comparative perspective' at the Max Weber Center for Advanced Cultural and Social Studies, Erfurt. I am grateful for suggestions and comments from my colleagues, especially Jörg Rüpke. Two anonymous reviewers raised important points, motivating a substantial change of perspective in the revised version.

2 I am referring to Fei's book Xiangtu Zhongguo (Fei 1947) which has been translated into English by Gary Hamilton and Wang Zheng under the title 'From The Soil: The Foundations of Chinese Society'. This translation raises interesting methodological issues, for example with reference to conceptualising the Chinese 'lineage' (see Harrell 2011). Hamilton (2014) puts Fei's thinking into the larger context of comparative studies on Western and Chinese culture. 
3 My approach is similar to Kulich's, who presented an overview of value studies building on both Western and Chinese research, especially focusing on the question of whether the etic standards of values, implied by using the same set of values across all cultures, needs to be modified by taking indigenous values into consideration (Kulich 2010; Kulich and Zhang 2010). The issue of indigenisation has been discussed intensively by Taiwanese psychologists, who argue in favour of a multi-dimensional approach to modernisation (see Yang 1989, 1998 and Hwang 2006).

4 See, for example, Yan 2010a. Case studies that highlight the paradox of individualisation and authoritarian education have been presented by Lin 2011 and Hansen 2013.

5 Tan (2010: 435ff) overviews different opinions in the Chinese literature, such as the idea that the traditional chaxu geju was based on moral order, whereas the modern chaxu geju is rationalised and hence 'instrumental'. Tan himself proposes the term gongjuxing quanceng geju that retains the ideas of social circles and hierarchical orders, but puts a 'family individualism' at the centre. Xiao (2010) goes back to a concept that was originally proposed by Fei himself in more recent work, the notion of 'differential arenas' chaxuchang, which catches the observation that rural people maintain social interactions in different domains (chang) that follow different principles of structuration.

6 Interestingly, Fei's approach comes close to another Asian perspective by the Japanese scholar Nakane Chie, which was also applied on Chinese social networks by King (1994). Chie distinguishes between 'frames' and 'attributes' as criteria of forming groups, with 'frames' being clearly demarcated categories and 'attributes' shared properties and relations.

7 Harrell (2011) points out that the prevailing view on the Chinese lineage was deeply shaped by Maurice Freedman and his studies of Hong Kong lineages (cf. Stafford 2000). Freedman transferred the standard conceptions of Western anthropology, not being aware of Fei's views. Fei distinguished between the patrilineal, i.e. surname-based groups (shizu), the jiating as the co-residential unit and the extended family (jiazu), arguing that the latter is built according to the open and flexible 'circle' principle. Interestingly, he did not use the term zongzu. In fact, what Freedman analysed was the zong (which corresponds to the shi in Fei's usage), i.e. the formally constituted descent group, which therefore can be interpreted along the 'Western' perspective, thus overlooking the underlying, different Chinese principles of network organisation. Only much later anthropologists discovered the factual variety and plural structures of Chinese lineages, both in contemporary conditions (e.g. Cohen 1990, who, based on fieldwork in North China, also uses jiazu as translating 'lineage') and in history (for example, Ebrey and Watson 1986 distinguish between the jia as the economically active unit, the $z u$ as the descent group including the matrilineal extension, and the zong as the formal principle of agnatic descent). What Freedman analysed as 'lineage' was the historical product also of active propagation of formal kinship organisation by the Imperial state, especially in South China (Faure 2007).

8 In his discussion of Fei's theory, Yan (2006) very much emphasises the rank order, criticising other interpretations of chaxu geju as overly emphasising horizontal network relationships. He goes beyond Fei in even positing a 'chaxu personality' chaxu renge. I think that this throws the baby out of the bathwater in overemphasising the official Confucian views of this rank order. Yan rightly points out that status is always relative to ego, thus contextualised, which introduces a principle of indeterminacy. Further, however, as I will argue later, the two principles of cha and $x u$ stay in a dynamic relationship, mutually balancing its impacts on actual behaviour.

9 The most recent version of Hofstede's work is Hofstede et al. 2010, which includes 
references to many independent uses and modifications of the original IBM survey and comparisons with other survey approaches to culture. Hofstede has always been active as an academic entrepreneur. Simple explanations of his cultural dimensions and comparative data can be retrieved from his company's website http:/ /geerthofstede.com/.

10 'Long term orientation' is still included as one single dimension in Hofstede et al. 2010. The partitioning happened after another researcher who joined the Hofstede team, Minkov, related the Hofstede approach to his own research on values. The six dimensions can be found on the Hofstede websites, such as http://geert-hofstede. $\mathrm{com} /$ national-culture.html.

11 The GLOBE approach is based on a large-scale coordinated survey effort with institutionally independent research teams in 62 countries (House et al. 2004). In comparison, the original Hofstede survey was based on a single multinational company in a comparable number of countries. Later, additions and extensions of the Hofstede survey were never done in a similarly concerted effort. So, the Hofstede approached evolved through time, whereas the GLOBE survey is a systematic snapshot at one particular point of time. The two protagonists are involved in controversies, mutually criticising their methodologies (e.g. Javidan et al. 2006).

12 On this methodological issue, see Beugelsdijk and Maseland 2010, section 5.3.2. If values reflect marginal valuations, we can compare changes of values across time for one particular country, but we cannot compare absolute levels across countries. This means that the most basic goal of etic value research is impossible to attain.

13 Hofstede et al. (2010: 40) clearly acknowledge that cultural scores refer to the society level exclusively, leaving much scope for individual variation. However, in his business applications the survey approach is also directly interpreted as generating information about individual-level characteristics. This is a major issue in criticising approaches such as Hofstede's, arguing that individual variation plays a systematic role in dynamically constructing culture (see Hong and Chiu 2001).

14 The 'dependence' paradigm was very influential in the literature on Chinese political culture originating in seminal studies such as Solomon 1971 and popularised in contributions such as Pye 1988. In the original approach, psychological literature on child socialisation was directly related to observations on political institutions. Although this approach indeed made a point on how values might be explained empirically, it was later abandoned. Walder's classical analysis $(1983,1986)$ only concentrates on the institutional setting of Maoist and early post-Maoist society, especially at the urban workplace, in generating 'dependence'. As a description of traditional culture, the dependence paradigm was decisively criticised by Metzger (1977) who instead proposed the paradigm of 'interdependence'.

15 Yan 2010b puts this observation against the background of recent sociological theorising about 'individualization' in 'reflexive modernisation'. In China, individualisation is often driven by 'forced disembedding' of individuals by the government and hence might even meet their resistance.

16 The most detailed and comprehensive critique of the Hofstede approach is unfortunately only available in German (see Behrens 2007). In meticulous detail she shows how Hofstede adapts and even distorts his data, combining them with often arbitrary interpretations of independent evidence, in order to end up in confirming what are basically common stereotypes about countries such as the US, France or the Netherlands. In particular, Hofstede clearly reveals an ethnocentric bias in positively evaluating Western European and American culture, and therefore often suppresses or re-interprets data which do not fit into the stereotypes. This is possible because Hofstede moves back and forth between statistical analysis, interpretations 
of single survey questions, and higher-level typologies of countries. I cannot go into detail here.

17 As Behrens (2007: 78ff) shows, for example, regarding 'individualism' Hofstede arbitrarily assigns individualistic phenomena in South European Catholic countries to expressions of power distance or masculinity, whereas less individualistic phenomena in the US are simply swept under the carpet. For the seminal paper that launched the thorough revision of the individualism/collectivism dichotomy in psychology see Oyserman et al. (2002). In management sciences, there is also a thorough critique of the Hofstede dualism in pointing out that cross-cultural contacts create a fuzzy border across behaviours, which is further bolstered also by more fundamental cognitive patterns, which I discuss in the next section; for a pertinent critique, see Fang (2010).

18 For a comprehensive survey of the literature, see Shavitt et al. 2012. The distinction goes back on Howard Triandis, one of the most influential psychologists working on the individualism/collectivism topic, see Triandis 1995. In comparison to Hofstede's or GLOBE's 'power distance', the verticality/horizontality distinction is not independent from the individualism/collectivism dichotomy, and it is not understood as a gradual scale with two poles. That means, combining the two dimensions results into four types of societies, which are themselves analytical, and not empirical categories.

19 For a summary of pertinent research, see Brewer and Chen (2007), and for an application in the Chinese context Liu et al. (2010). The term 'categorial collectivism' was introduced in Herrmann-Pillath 2009: Brewer and Chen use 'group collectivism' which I find less specific and therefore confusing.

20 An exemplary study is Sanchez-Burks et al. (2003), who investigated the role of personal relations in workplace vs. non-workplace interactions and showed that differences between Americans and East Asians are more pronounced in a workplace setting, with Americans paying significantly less attention to relational cues. Workplace interactions also contribute to affect-based trust among Chinese subjects (see Chua et al. 2009).

21 On 'relational personalism', see Gabrenya and Hwang 1996. One can relate this to Charles Taylor's (1989) philosophical analysis of modern individualism. Taylor distinguishes two different European traditions, one is the rational form of individualism, emphasising formal rights, autonomy of agency and so forth, and the other is the 'expressivist' tradition, which emphasises individual creativity in social relationships. This dualism persists until today, for example in the shape of libertarianism vs. communitarism.

22 Behrens (2007: 80ff) has an extensive discussion of the methodological issues in constructing cultural typologies based on 'cultural dimensions' such as Hofstede's. For example, do countries with a similar score in 'power distance' also belong to one 'type'? Or does the peculiar pattern of interaction between dimensions define types? The other possibility, which I favour, is to treat the dimensions only as analytical categories ('aspects'), and build the typology on other criteria, such as historical ones. 'Confucianism' then turns out to be a very weak category for defining a 'type' for East Asian societies (see the contributions in Rozman 1991).

23 For an overview of this rich literature, see Bowles and Polonía-Reyes (2012). For example, framing effects determine whether a pecuniary sanction is perceived as a 'punishment' or a 'payment', implying market-like reciprocity. In the latter case, individualistic behaviour is bolstered. Behavioural flexibility and contextualisation has been observed in criticising the Hofstede approach for long, see the overview in Fang (2010). 
24 The contextualisation of behaviour is also highlighted in the related approach of 'dynamic constructivism' championed by Hong Ying-yi and colleagues (Hong et al. 2000, 2001). For example, they could show that certain value orientations switch in the case of bilingual Chinese subjects from Hong Kong, depending on which cultural stances are triggered by cues (such as Chinese vs. American icons).

25 See Nisbett (2003), building on empirical research such as Ji et al. $(2000,2004)$. These notions originated in earlier literature about the effects of the social environment on cognition, see, for example, Boyd and Richerson (1985: 178ff). 'Field dependence' can be empirically tested by means of standardised psychological tests such as the 'rod and frame test' where subjects have to identify the slope of a line put in alternating frames. In case of field-dependence, the perception of the slope is more strongly influenced by the frame.

26 For an interesting experiment, see Chen et al. 2007, who work with the distinction between 'idiocentric' and 'allocentric' attitudes and apply the so-called 'public goods game' in order to identify value orientations of individuals. In such games there are strong incentives for cheating. Chinese subjects react strongly when they perceive a group norm of cooperation, whereas American subjects exploit this information for individual benefit. The authors distinguish this pattern from a pattern of 'group identity' in which the individuals would directly adopt group interests, which could not be confirmed. Whereas the researchers think that these differences reflect 'cultural values', the results can also be explained in terms of different degrees of field dependence.

27 This has been shown in the recent study by Talhelm et al. (2014) who provide empirical evidence for differences in terms of 'individualism', 'analytical thought' and so forth within China, with the different agrarian ecologies as the single most important causal factor of the differences. However, this argument has been put forward for decades in the Asian studies literature (for example, Wilhelm 1930), and can be even traced back to literary stereotypes about North and South China in Chinese tradition.

28 The classic treatment of guanxi, also in the rural/urban comparison, is Yang (1994). Guthrie (1998) presented the critical position arguing that globalisation is undermining traditional guanxi practices in the cities; this was partly refuted by Yang (2002), emphasising gender aspects and modern transformations of guanxi-based behaviour (see also Wank 2002). Further, the association of guanxi and corruption also means that guanxi practices might be work in the background and are unlikely to be openly thematised. This partly explains the career of the concept in the 1980s and 1990s, when Western researchers 'discovered' the guanxi term (see Gold et al. 2002: 3ff), whereas Chinese informants were initially reluctant to refer to it.

29 On the li shang wanglai notion, see Chang (2010) who sees guanxi only as one aspect of Chinese social networks which is not necessarily positively evaluated. Another author who emphasises this larger framework is Stafford (2000). These studies focus on the rural areas where classical research of guanxi as networks of mutual support and gift giving have been realized, such as Kipnis (1996) or Yan (1996a, b). The expression li shang wanglai goes back to the Confucian classic 'Book of Rites' where it denotes the proper rules of reciprocity in a feudal status order.

30 The classical guanxi model has been developed by Jacobs (1982) and distinguishes between three 'guanxi bases', shared, but essentially arbitrary identities (tong), emotional exchange (ganqing) and instrumental value. The emotional foundation turns guanxi dyadic, as relationships between individuals matter, whereas the shared identity renders networks open, as individuals can create a manifold of criss-crossing network identities. For a more recent model that matches with my short summary, see Chen and Chen (2004). 
31 On a related interpretation, see $\mathrm{Li}$ (2007). The notion of social capital as a means to gain individual advantage from network positions and relations is elaborated in Lin (2001).

32 This role of the self has been elaborated clearly in King's 1994 influential analysis, which sees the 'self' $j i$ as the 'architect' of social relations, which is reasserted by more recent management science receptions such as Chen and Chen 2004. Interestingly, this view matches with sinological studies of Confucian ethics such as Metzger 1977 who emphasises the self as a moral agent. Hall und Ames (1998: 23ff) introduce the term 'focus field self'. Regarding the practical management of guanxi, contributions as early as De Glopper (1978), and more recently Kipnis (2002), have emphasised that in many business relationships, the emotional commitment of guanxi is explicitly avoided in order to reduce the corresponding obligations.

33 The 'Inglehart-Welzel Cultural map' of the world can be retrieved from http:/ / www. worldvaluessurvey.org/WVSContents.jsp. For the subsequently reported data of the WVS, the WVS website offer an online data analysis service by which users can produce their own excel sheets and diagrams. The website also offers methodological background information. Research in China was realized by Shen Mingming and Yan Jie of the Peking University Research Center for Contemporary China. They applied advanced sampling methods that have also been applied and described in Whyte (2010).

34 Kulich (2010: Chapter 8) confirms evidence from other approaches to values studies, such as combining research into most cited proverbs and Schwartz's value survey. The Chinese always appear to emphasise individual performance, effort and responsibility for one's own fate.

35 Zhai (2011: 127ff) distinguishes between 'authority' flowing from social structure and 'ordinary life authority' resulting from guanxi, which can soften or even undermine the former. This observation puts Yan's (2006) view into perspective that verticality dominates the chaxu geju, in the sense of social structure shaping horizontal relations. Accordingly, Yang (1994) distinguished between 'arborean networks' and 'rhizomatic networks', with the latter prevailing in China.

36 For an excellent overview on the role of modernist ideologies in shaping the view on religion in twentieth century China, see Goossaert and Palmer (2011). For example, in the 1920s Buddhism reformed itself partly in following organisational patterns of Christian churches. On the contrary, almost all political elites and intellectuals condemned popular religion as being mere 'superstition', thus driving a deep wedge between the project of modernisation and nation-building on the one hand and on the other hand the full recognition of Chinese cultural tradition (compare Lagerwey 2010: 154).

37 See Chau (2011, 2012, 2014). The term 'polytropy' was introduced into the study of religion by Michael Carrithers and refers to the observation that in many regions in the world, especially in Asia, 'believers' switch between different religious beliefs and practices according to their individual needs, so that there is no unique ascription of individuals to certain mutually exclusive religious denominations. This happens even if the denominations themselves might be organised in church-like structures.

38 It is interesting to compare this analysis with Foucault's (2004: 177ff., 187) analysis of the 'shepherd' in Medieval Christianity. Here, absolute submission to the religious authority is required, leaving no individual choice of religious practices. The individual becomes a member of a religious community and loses its autonomy.

39 The orthodoxy/orthopraxy distinction was introduced by James Watson (1985/2004), see also Watson and Rawski (1988), into Chinese studies in order to understand the 
specific interaction between religion and government control in China. The Imperial state allegedly focused on ritual control in certain sensitive areas ('orthopraxy') and did not interfere with the beliefs that people actually held even about those statecontrolled rituals. There is a lively debate over this view, see Sutton (2007) and the accompanying special issue of 'Modern China'.

40 On the ambivalent nature of this celestial bureaucracy, which mirrors the tension between orthopraxy and heterodoxy, that is deviant interpretations of religious symbols and practices, see the classical analysis by Feuchtwang 1992.

41 On applications of the model in Chinese contexts, see Yang (2006) or Lu et al. (2008). Chau (2011) also refers his model of modalities to the religious market model. Palmer (2011) is a thorough critique of the model arguing that the market paradigm does not cover the essential role of gift relationships in Chinese religion. This critique does not invalidate my point on individualism, but rather broadens the scope in including two different expressions of individualism (actually, in a Taylorian vein, Taylor 1986). Gift exchange is also driven by individual initiative and religious autonomy.

\section{REFERENCES}

Bergren, Niklas, Mikail Elinder, and Henrik Johrdahl 2008. Trust and Growth: A Shaky Relationship'. Empirical Economics, 35: 251-74.

Beugelsdijk, Sjoerd, Maseland, Robert 2010. Culture in Economics. History, Methodological Reflections, and Contemporary Applications. Cambridge: Cambridge University Press.

Bowles, Samuel and Sandra Polanía-Reyes 2012. 'Economic Incentives and Social Preferences: Substitutes or Complements, Journal of Economic Literature', 50(2): 368-425.

Boyd, Richard and Richerson, Peter J. 1985. Culture and the Evolutionary Process, Chicago and London: University of Chicago Press.

Brewer, Marilynn B. and Ya-Ru Chen 2007. 'Where (Who) Are Collectives in Collectivism? Toward Conceptual Clarification of Individualism and Collectivism'. Psychological Review, 114(1): 133-151.

Chang, Weining C. and Lynn Lee 2012. 'The Concentric Circle Revisited: Allocentrism and Self in a Contemporary Chinese Community'. Psychology, 3(4): 297-303.

Chang, Xiaoqun 2010. Guanxi or Li shang wanglai? Reciprocity, Social Support Networks, $\mathcal{E}$ Social Creativity in a Chinese Village. Taipei: Ariti Press.

Chau, Adam Y. 2011. 'Modalities of Doing Religion and Ritual Polytropy: Evaluating the Religious Market Model from the Perspective of Chinese Religious History'. Religion, 14(4): 547-568.

Chau, Adam Y. 2012. Efficacy, not Confessionality: On Ritual Polytropy in China. In Bowman, G., ed., Sharing the 'Sacra': The Politics and Pragmatics of Intercommunal Relations Around Holy Places, Oxford, 79-96.

Chau, Adam Y. 2014. 'Household Sovereignty and Religious Subjectification: China and the Christian West Compared'. Studies in Church History, 50: 494-506.

Chen, Chao C. Chen, Xiao-Ping and Huang, Shengsheng 2013. 'Chinese guanxi: An Integrative Review and New Directions for Future Research'. Management and Organization Review, 9(1): 167-207.

Chen, Xiao-Ping, Chen, Chao C. 2004. 'On the Intricacies of the Chinese Guanxi: A Process Model of Guanxi Development'. Asia Pacific Journal of Management, 21: 305-324.

Chen, Xiao-Ping, Wasti, S. Arzu, Triandis, Harry C. 2007. 'When Does Group Norm 
or Group Identity Predict Cooperation in a Public Goods Dilemma? The Moderating Effects of Idiocentrism and Allocentrism'. International Journal of Intercultural Relations, 31: 259-276.

Chua, Roy Y. J., Morris, Michael W., Ingram, Paul 2009. 'Guanxi vs. Networking: Distinctive Configurations of Affect- and Cognition-based Trust in the Networks of Chinese vs American Managers'. Journal of International Business Studies, 40: 490-508.

Cohen, Myron L. 1990. 'Lineage Organization in North China'. Journal of Asian Studies, 49(3): 509-534.

De Glopper, Donald R. 1978. 'Doing Business in Lukang'. In: Wolf, A., ed. Studies in Chinese Society, Stanford: Stanford University Press: 209-226.

Ebrey, Patricia B. and Watson, James L. 1986. 'Introduction'. In: Ebrey, P. B. and Watson, J. L., eds., Kinship Organization in Late Imperial China, 1000-1949, Berkeley, Los Angeles, London: University of California Press, 1-15.

Fang, Tony 2010. 'Asian Management Research Needs More Self-confidence: Reflections on Hofstede (2007) and Beyond'. Asia Pacific Journal of Management, 27: 155-170.

Fang, Tony 2012. 'Yin Yang: A New Perspective on Culture'. Management and Organization Review, 8(1): 25-50.

Faure, David 2007. Emperor and Ancestor: State and Lineage in South China, Stanford: Stamford University Press.

Fei Hsiao-tung (Xiaotong) 1939. Peasant Life in China. A Field Study of Country Life in the Yangtze Valley. London und Henley: Routledge and Kegan Paul.

Fei Hsiao-tung (Xiaotong), Chang, Chih-I. 1945. Earthbound China. A Study of Rural Economy in Yunnan, Chicago: University of Chicago Press.

Fei Xiaotong. 1947. Xiangtu Zhongguo, Shanghai. Translation by Gary Hamilton and Wang Zheng, From the Soil. Foundations of Chinese Society, Berkeley: University of California Press, 1988.

Feuchtwang, Stephen 1992. The Imperial Metaphor. Popular Religion in China. London und New York: Routledge.

Foucault, Michel 2004. Sécurité, territoire, population. Cours au Collège de France, 19771978. Paris: Seuil.

Gabrenya, William K. and Hwang Kwang-Kuo 1996. ,Chinese Social Interaction: Harmony and Hierarchy on the Good Earth'. In: Bond, M. H., ed., The Handbook of Chinese Psychology, Hong Kong: Oxford University Press: 309-21.

Gold, Thomas, Guthrie, Doug, Wank, David, eds. 2002. Social Connections in China. Institutions, Culture, and the Changing Nature of Guanxi. Cambridge: Cambridge University Press.

Goossaert, Victor Palmer, David A. 2011. The Religious Question in Modern China, Chicago: Chicago University Press.

Guiso, Luigi, Sapienza, Paolo, Zingales, Luigi 2006. 'Does Culture Affect Economic Outcomes?'. Journal of Economic Perspectives, 20(2): 23-48.

Guthrie, Doug 1998. 'The Declining Significance of guanxi in China's Economic Transition'. The China Quarterly, 154: 254-282.

Hall, David L. and Ames, Roger T. 1998. Thinking From the Han. Self, Truth, and Transcendence in Chinese and Western Culture, New York: SUNY Press.

Hall, Edward T. 1976. Beyond Culture, New York: Anchor Books.

Hamilton, Gary G. 2014. 'What can Western Social Scientists Learn from the Writings of Fei Xiaotong?', Journal of China in Comparative Perspective 1(2), http:/ / www.journal. ccpn-global.org/cms.php?artid=489\&catid $=231$

Hansen, Mette H. 2013. 'Learning Individualism: Hesse, Confucius, and Pep-Rallies in a Chinese Rural High School'. The China Quarterly, 213: 60-77.

Hansen, Mette H., Svarverud, Rune, eds. 2010. iChina: The Rise of the Individual in Modern 
Chinese Society. Copenhagen: NIAS Press.

Harrell, Stevan 2011. 'Fei Xiaotong and the Vocabulary of Anthropology in China'. Journal of China in Comparative Perspective 1(1), http:/ / www.journal.ccpn-global. org $/$ cms.php?artid $=804 \&$ catid $=510$

Herrmann-Pillath, Carsten 1995. 'On the Importance of Studying Late Qing Economic and Social History for the Analysis of Contemporary China, or: Protecting Sinology Against Social Science'. Duisburger Arbeitspapiere Ostasienwissenschaften Nr. 3, Institut für Ostasienwissenschaft der Gerhard Mercator Universität GH Duisburg.

Herrmann-Pillath, Carsten 2009. 'Social Capital, Chinese Style: Individualism, Relational Collectivism and the Cultural Embeddedness of the Institutions-Performance Link'. China Economic Journal, 2(3): 325-350.

Hofstede, Geert, Hofstede, Gert Jan, Minkov, Michael 2010. Cultures and Organizations. Software of the Mind, New York: McGrawHill.

Hong, Ying-yi and Chiu, Chi-yue 2001. 'Toward a Paradigm Shift: From Cross-cultural Differences in Social Cognition to Social-cognitive Mediation of Cultural Differences'. Social Cognition, 19(3): 181-196.

Hong, Yingyi, Ip, Grace, Chiu, Chi-yue, Morris, Michael W. and Menon, Tanya 2001. 'Cultural Identity and Dynamic Construction of the Self: Collective Duties and Individual Rights in Chinese and American Cultures'. Social Cognition, 19(3): 251-268.

Hong, Ying-yi, Morris, Michael W., Chiu, Chi-yhue and Benet-Martinéz, Veronica 2000. 'Multicultural Minds: A Dynamic Constructivist Approach to Culture and Cognition'. American Psychologist, 55(7): 709-720.

House, Robert J., Hanges, Paul J., Javidan, Mansour, Dorfman, Peter W. and Gupta, Vipin, eds. (2004) Culture, Leadership, and Organizations. The Globe Study of 62 Societies, Thousand Oaks, London, New Delhi: Sage.

Hwang, Kwang-Kuo 2006. 'Constructive Realism and Confucian Relationalism: An Epistemological Strategy for the Development of Indigenous Psychology'. In: Kim, U., Yang, G.-S, Hwang, K.K., eds., International and Cultural Psychology: Understanding People in Context, New York: Springer: 73-107.

Inglehart, Ronald and Welzel, Christian 2005. Modernization, Cultural Change, and Democracy: The Human Development Sequence, Cambridge: Cambridge University Press.

Jacobs, J. Bruce 1982. 'The Concept of Guanxi and Local Politics in a Rural Chinese Cultural Setting. In S. Greenblatt, Wilson, R. W., Wilson, A. A., eds., Social Interaction in Chinese Society, New York: Praeger: 209-236.

Javidan, Mansour, House, Robert J., Dorfman, Peter W., Hanges, Paul J., and de Luque, Mary S. 2006. 'Conceptualizing and Measuring Cultures and Their Consequences: a Comparative Review of GLOBE's and Hofstede's Approaches'. Journal of International Business Studies, 37: 897-914.

Ji, Li-Jun, Lee, Albert, Guo, Tieyuan 2010. 'The Thinking Styles of Chinese People'. In Bond, M. H., eds., The Oxford Handbook of Chinese Psychology, Oxford, New York: Oxford University Press: 241-278.

Ji, Li-Jun, Nisbett, Richard E., Peng, Kaiping 2000. 'Culture, Control, and Perception of Relationships in the Environment', Journal of Personality and Social Psychology, 78(5): 943-955.

Ji, Li-Jun, Nisbett, Richard E., Zhang, Zhiyong 2004. 'Is It Culture or Is It Language? Examination of Language Effects in Cross-Cultural Research on Categorization'. Journal of Personality and Social Psychology, 87(1): 57-65.

King, Ambrose Y.-c. 1994. 'Kuan-hsi and Network Building: A Sociological Interpretation'. In: Tu, W., ed., The Living Tree. The Changing Meaning of Being Chinese Today, Stanford: Stanford University Press, 109-126.

Kipnis, Andrew 1996. 'The Language of Gifts: Managing Guanxi in a North China 
Village', Modern China, 22(3), 285-314.

Kipnis, Andrew 2002. 'Practices of Guanxi Production and Ganqing Avoidance'. In Gold, T., Guthrie, D., Wank, D., eds. Social Connections in China. Institutions, Culture, and the Changing Nature of Guanxi, Cambridge: Cambridge University Press: 21-36.

Kipnis, Andrew, ed. 2012. Chinese Modernity and the Individual Psyche, New York: Palgrave.

Kulich, S. J. 2010. Applying Cross-Cultural Values Research to "the Chinese": A Critical Integration of Etic and Emic Approaches, Dissertation Humboldt Universität Berlin.

Kulich, Steve J., Zhang Rui 2010. ,The Multiple Frames of Chinese 'Values': From Tradition to Modernity and Beyond'. In: M. H. Bond, ed., The Oxford Handbook of Chinese Psychology, Oxford, New York: Oxford University Press, 241-278.

Lagerwey, James 2010. China: A Religious State, Hong Kong: Chinese University Press.

Li, Peter P. 2007. 'Guanxi as the Chinese Norm for Personalized Social Capital: Toward an Integrated Duality Framework of Informal Exchange'. In: Yeung, H. W.-C., ed., Handbook of Research on Asian Business. Cheltenham und Northampton: Edward Elgar, 62-83.

Li, Peter P. 2014. 'The Unique Value of Yin-Yang Balancing: A Critical Response'. Management and Organization Review, 10(2): 321-332.

Li Xin 2014. 'Can Yin-Yang Guide Chinese Indigenous Management Research?'. Management and Organization Review, 10(1): 7-27.

Lin, Nan (2001): Social Capital. A Theory of Social Structure and Action, Cambridge: Cambridge University Press.

Lin, Yi 2011. 'Turning Rurality into Modernity: Suzhi Education in a Suburban Public School of Migrant Children in Xiamen'. The China Quarterly, 206: 313-330.

Liu, James H., Li Mei-chi, Yue Xiaodong 2010. ,Chinese Social Identity and Inter-group Relations: the Influence of Benevolent Authority'. in: Bond, M. H., ed., The Oxford Handbook of Chinese Psychology, Oxford: Oxford University Press: 579-598.

Metzger, Thomas A. 1977. Escape From Predicament. Neo-Confucianism and China's Evolving Political Culture. New York: Columbia University Press.

Nisbett, Richard E 2003, The Geography of Thought: How Asians and Westerners Think Differently... and Why, New York: Free Press.

Oyserman, Daphna, Coon, Heather M., Kemmelmeier, Markus 2002. 'Rethinking Individualism and Collectivism: Evaluation of Theoretical Assumptions and Metaanalysis'. Psychological Bulletin, 46(3): 598-609.

Palmer, David 2011. 'Gift and Market in the Chinese Religious Economy'. Religion, 41(4): 569-594.

Pye, Lucian W. (1988). The Mandarin and the Cadre: China's Political Cultures, Ann Arbor: University of Michigan.

Rozman, Gilbert, ed. (1991) The East Asian Region. Confucian Heritage and Its Modern Adaptation, Princeton: Princeton University Press.

Shavitt, Sharon, Torelli, Carlos J, Riemer, Hila 2011. 'Horizontal and Vertical Individualism and Collectivism: Implications for Understanding Psychological Process'. In Gelfland, M.J., Chiu, C.-y., Hong, Y.-y., eds. Advances in Culture and Psychology, Volume One, Oxford and New York: Oxford University Press, 309-350.

Solomon, Richard H. 1971. Mao's Revolution and the Chinese Political Culture. Berkeley, Los Angeles, London: University of California Press.

Stafford, Charles 2000. 'Chinese Patriliny and the Cycles of Yang and Laiwang'. In Carsten, J., ed., Cultures of Relatedness: New Approaches to the Study of Kinship, Cambridge: Cambridge University Press, 35-54.

Stenner, Karen 2005. The Authoritarian Dynamic. Cambridge: Cambridge University Press. 
Sutton, Denis S. 2007. 'Ritual, Cultural Standardization, and Orthopraxy in China: Reconsidering James L. Watson's Ideas'. Modern China, 33(1), 3-21.

Talhelm, T., Zhang, X., Oishi, S., Shimin, C., Duan, D., Lan, X., Kitayama. S. 2014. 'Large-Scale Psychological Differences within China Explained by Rice versus Wheat Agriculture'. Science, 344(6184): 603-608.

Tan Tongxue 2010. Qiao cun you dao. Zhuanxing xiangcun de daode quanli yu shehui jiegou (The Way of Qiao Village. Moral Rights and Social Structure in Transforming Rural Society) Beijing: San lian shudian.

Taylor, Charles M. 1989. Sources of the Self. The Making of Modern Identity, Cambridge: Harvard University Press.

Triandis, Harry C. 1989. 'The Self and Behaviour in Differing Cultural Contexts'. Psychological Review, 96: 506-520.

Triandis, Harry C. 1995. Individualism \& Collectivism, Boulder: Sharpe.

Walder, Andrew G. 1983. 'Organized Dependency and Cultures of Authority in Chinese Industry'. Journal of Asian Studies, XLIII(1): 51-76.

Walder, Andrew G. 1986. Communist Neo-Traditionalism: Work and Authority in Chinese Industry, Berkeley: University of California Press.

Wank, David 2002. 'Business-State Clientilism in China: Decline or Evolution?' In Gold, T., Guthrie, D., Wank, D., eds., Social Connections in China. Institutions, Culture, and the Changing Nature of Guanxi, Cambridge: Cambridge University Press, 97-115.

Watson, James L., Watson, Rubie S. 2004. Village Life in Hong Kong. Politics, Gender, and Ritual in the New Territories, Hong Kong: Chinese University Press.

Watson, James, Rawski, Evelyn, eds. 1988. Death Ritual in Late Imperial and Modern China, Berkeley: University of California Press.

Whyte, Martin K. 2010. Myth of the Social Volcano. Perceptions of Inequality and Distributive Injustice in Contemporary China, Stanford: Stanford University Press.

Wilhelm, Richard 1930. Chinesische Wirtschaftspsychologie, Leipzig: Deutsche Wissenschaftliche Buchhandlung.

Xiao Lou 2010. Xia cun shehui. Zhongguo 'jiangnan' nongcun richang shenghuo he shehui jiegou (1976-2006), (The Society of Xia village. Everyday Life and Social Structure in Jiangnan Villages of China), 1976-2006, Beijing: Sanlian shudian.

Yamagishi, Toshio 2012. 'Micro-Macro Dynamics of the Cultural Construction of Reality. A Niche Construction Approach to Culture'. In Gelfland, Michele J., Chi-yue Chiu and Ying-yi Hong (eds), Advances in Culture and Psychology, Volume One, Oxford and New York: Oxford University Press, 251-308.

Yan Yunxiang 1996. 'The Flow of Gifts. Reciprocity and Social Networks in a Chinese Village'. Stanford: Stanford University Press.

Yan Yunxiang 1996. 'The Culture of Guanxi in a North China Village'. The China Journal, 35: 1-26.

Yan Yunxiang 2006. 'Chaxu geju yu Zhongguo wenhua de dengjiguan (The Differential Mode of Association and the View on Hierarchy in Chinese Culture). Sociological Studies Shehuixue yanjiu, 2006/4: 201-212.

Yan Yunxiang2010a. 'The Chinese Path to Individualization' British Journal of Sociology, 61(3): 489-512.

Yan Yunxiang 2010b. 'Introduction: Conflicting Images of the Individual and Contested Process of Individualization'. In: Hansen, M. H., Svarverud, R, eds. 2010. iChina: The Rise of the Individual in Modern Chinese Society, Copenhagen: NIAS Press, 1-39.

Yang Ching Kun 1961. Religion in Chinese Society: A Study of Contemporary Social Functions of Religion and Some of Their Historical Factors, Berkeley: University of California Press.

Yang Kuo-shu 1996. 'Psychological Transformation of the Chinese People as a Result 
of Societal Modernization'. In Bond, M. H., ed., The Handbook of Chinese Psychology, Hong Kong: Oxford University Press, 479-498.

Yang Kuo-shu. 1989. Zhongguo ren de tuobian (The Metamorphosis of the Chinese), Taibei: Guiguan tushu gongsi.

Yang, Mayfair M.-h. 1994. Gifts, Favours and Banquets: The Art of Social Relationships in China, Ithaca: Cornell University Press.

Yang, Mayfair M.-h. 2002. 'The Resilience of Guanxi and Its New Deployments A Critique of Some New Guanxi Scholarship'. In: The China Quarterly, 170: 459-476.

Yang, Mayfair M.-h. 2007. 'Ritual Economy and Rural Capitalism with Chinese Characteristics' In: Held, D., Moore, H., ed., Cultural Politics in a Global Age: Uncertainty, Solidarity and Innovation, Oxford: Oneworld: 216-223.

Zhai Xuewei 2011. Zhongguo ren de guanxi yuanli. Shikong zhixu, shenghuo yunian ji qi liubian (The Principles of Chinese Guanxi. Time-space Order, Life Desire and Their Changes). . Beijing: Peking University Press.

Zhai Xuewei 2013. Renqing, mianzi yu quanli zaishengchan (Face, Favour and the Reproduction of Power) Beijing: Peking University Press. 